Gibb, K., Osland, L., and Pryce, G. (2014) Describing inequalities in access to employment and the associated geography of wellbeing. Urban Studies, 51 (3). pp. 596-613. ISSN 0042-0980

Copyright (C) 2013 Urban Studies Journal Limited.

A copy can be downloaded for personal non-commercial research or study, without prior permission or charge

The content must not be changed in any way or reproduced in any format or medium without the formal permission of the copyright holder(s)

When referring to this work, full bibliographic details must be given

http://eprints.gla.ac.uk/84743/

Deposited on: 18 February 2014

Enlighten - Research publications by members of the University of Glasgow http://eprints.gla.ac.uk 


\title{
Describing Inequalities in Access to Employment and the Associated Geography of Wellbeing
}

\author{
Kenneth Gibb \\ Urban Studies, \\ University of Glasgow, Glasgow, Scotland G12 8RS \\ kenneth.gibb@glasgow.ac.uk \\ Liv Osland \\ Stord/Haugesund University College, \\ Bjørnsonsgt 45, N-5528 Haugesund, Norway \\ liv.osland@hsh.no \\ and \\ Gwilym Pryce* \\ Urban Studies, \\ University of Glasgow, Glasgow, Scotland G12 8RS \\ gwilym.pryce@glasgow.ac.uk
}

* Corresponding author

\begin{abstract}
:
This paper addresses three questions: (1) How unequal is access to urban employment and the wellbeing associated with it? (2) What is the monetary value consumers place on access? (3) How does the inequality of access correspond to the geographical pattern of unemployment? We develop a novel approach using the Osland \& Pryce (2012) house price model to estimate the Monetary Value of Access Welfare (MVAW) - the wellbeing associated with living a given distance to employment, taking into account the negative externalities associated with centres of employment, and the complexities that arise from the existence of multiple employment centres of varying size. We find that: (1) MVAW is considerably more unequal than house prices or income; (2) MVAW contributes around $13 \%$ of the average value of a house; and (3) the spatial pattern of unemployment rates are highly inelastic with respect to both MVAW and employment, suggesting no evidence of a spatial mismatch.
\end{abstract}

Key words: Employment Access, Spatial Mismatch, Inequality, Hedonic Estimation

\section{Acknowledgements}

This research was part-funded by: (1) the Department of Communities and Local Government; (2) the Adam Smith Research Foundation, (3) the EPSRC Socio-economic Model and Community Impact Simulators project (EPSRC CREW grant reference: EP/F037716/1), and (4) the Research Council of Norway (research programme 182639/V10). We are grateful to Roger Bivand for giving helpful suggestions during the work on this paper, and to GSPC for providing the house price data. 


\section{Introduction}

How can we measure the inequality in wellbeing (household utility) that arises from unequal access to urban employment? It is a slippery question because poor access to employment may affect other variables, such as the ability to find work, or how easy it is to find the job that best matches one's skills. If land prices rise with access to employment, there may be vicious circles at work as those on low wages are screened out of the best placed housing. In the long term, how much those on high wages will outbid those on low wages for a house with easy access will reflect the increase in welfare associated with having good access to employment. It follows that the value of a dwelling should rise and fall with the value of employment access, once other factors have been controlled for (such as property attributes and access to amenities).

The problem is complicated by the existence of multiple employment centres of varying size (in a non-monocentric city), and negative externalities (e.g. pollution) associated with employment centres. Our goal is to account for such complexities using a hedonic house price model which includes a gravity-based accessibility measure that allows for non-monotonic distance effects, where the non-monotonic part captures the negative externalities of living too close to an employment centre. We use the hedonic model to estimate the wellbeing associated with residential location at a given distance from employment. We call this "Access Welfare" and attempt to ascribe to it a meaningful scale by estimating its monetary value. We also seek to gauge how unequal is this form of wellbeing. If it is perfectly equally distributed across residences then problems, such as spatial mismatch between the location of work and those seeking work, will be precluded. Finally, we investigate whether there is any correspondence between Access Wellbeing and the geographical pattern of unemployment. Our results suggest that, in Glasgow, the distribution of Access Welfare is highly unequal, but the relationship between unemployment and Access Welfare is highly inelastic and possibly zero.

The paper is structured as follows. Section 1 reviews the existing literature. Section 2 states our research questions. Section 3 summarises the main methodological challenges, and our proposed solutions. Section 4 describes our data and section 5 presents the results of our regression analysis. Section 6 concludes. 


\section{Literature Review on Urban Space, Inequality and Employment Accessibility}

This short, selective review integrates findings from three broad urban literatures: spatial/skills mismatch; the urban land rent gradient and the empirical analysis of inequality across urban space. These three literatures correspond directly to the principal goals of the paper: the inequality of access to employment across urban space, the monetary value placed on that access and the urban spatial relationship between employment and wider inequality. In different ways the literature explains location patterns of an urban area and points to mechanisms relevant for our research questions.

\section{Spatial Mismatch Hypothesis}

Much of the research on the relations between poverty and spatial separation of home and work has focused on spatial mismatch (Blumenberg and Manville, 2004). Pioneered by Kain (1968), the hypothesis that there may be a disconnect between the location of employment and the location of the unemployed has generated extensive empirical investigation (see Ihlanfeldt and Sjoquist, 1998; Kain, 2004; Houston, 2005; and Gobillon et al., 2007). Kain originally sought to 'describe a broad set of geographical barriers to employment for African-American inner city residents' (Preston and McLafferty, 1999, p.388). Suburbanisation of jobs and residential segregation or sorting into predominantly inner city housing created difficult trade-offs between housing costs, transport and acceptable wages which in turn led to higher degrees of black worklessness and further reinforcement of ethnic spatial segregation and inequality. Subsequent research has sought confirmatory evidence of these forces in a range of different ways. The empirical evidence of the hypotheses varies considerably across time, space and subpopulation (e.g. Ihlanfeldt and Sjoquist, 1998; Preston and McLafferty, 1999; Gobillon et al., 2007; Turok and Webster, 1998; Houston, 2005).

Papers in this vein have also contributed to policy analysis in response to the mismatch focusing on housing market discrimination, labour market information and search policies and a series of initiatives to weaken the commuting cost constraint. Of course, these analyses are founded on different conceptualisations of urban labour markets - such as the extent to which the labour market is segmented or in fact can draw in mobile labour from across the metropolitan system (Morrison, 2005). In this regard the Gobillon et al. (2007) paper is particularly useful in that it moves beyond empirical 
confirmation of one form or another of the hypothesis and instead attempts to understand the underlying process, identifying seven mechanisms of mismatch (p.2408-09):

1. workers may refuse jobs involving commutes that are excessively long or costly relative to the expected wage

2. worker job search efficiency may decrease with distance to the job

3. workers who live far away from jobs may not search sufficiently intensively

4. search costs may lead them to restrict their search space

5. employers may discriminate against residentially segregated potential workers

6. employers may refuse to hire or offer lower wages to long commuters because of concerns about lower productivity

7. suburban employers may think their customers will discriminate against minority workers from the city.

Gobillon, et al., find 'clear evidence supporting the effect of commuting costs and customer discrimination on unemployment. There is also suggestive evidence that the increase in search costs and the decrease in search efficiency with distance can cause unemployment. However, it appears that the search incentive, productivity and redlining assumptions have not [yet] been empirically investigated' (p.2419).

\section{Land Rent Gradients}

Our goal is to consider how house prices reflect the utility associated with access to employment. In the standard monocentric urban economic model, the land rent gradient, reflecting the value of a standardised unit of land, will fall at a diminishing rate from the city centre due to rising commuting costs (e.g. Evans, 1985, p.24). The causes and effects of the land rent gradient have been used to explain allocations of land to different uses across space and as the foundation of empirical outcomes (Alonso, 1964; Muth, 1969; Mills, 1972; Anas et al., 1998; McDonald and McMillen, 2007), though the evidence has been mixed due to the well-known restrictiveness of the model's assumptions (Maclennan, 1982) and the lack of good data (McDonald and McMillen, 2007, p.149).

Polycentricism and the decentralisation of specific sectors such as manufacturing and certain economic services - captured in Garreau's Edge City concept - have brought the rent gradient concept into disrepute. Theoretical studies suggest that employment subcentres arise where built-up areas become sufficiently large and have tipped into high 
congestion costs, incentivising firms to leave the central business district (CBD) (McDonald and McMillen, 2007, p.171). As a result, the empirical researcher may need to uncover and investigate a larger number of rent gradients associated with employment subcentres, residential neighbourhoods and transport nodes across cities and metropolitan regions (Anas et al., 1998).

\section{Theoretical analyses of inequality across urban space.}

Traditional urban economic theory and the Tiebout (1956) model are basic references that provide predictions on the spatial distribution of people in different income groups. A core idea of the trade-off model of urban economics is that higher income groups have an elastic income demand for space and consequently households are sorted by space with higher income groups suburbanising. In the Tiebout model, suburbanisation of high income groups is due to high taxes, low quality schools and other government services, racial tensions, crime, congestion and low environmental quality (Mieszkowski and Mills, 1993 p.137). There are, however, many contemporary cities and nations where higher income groups are found in city centres (Brueckner et al., 1999). We have also already seen one interpretation of the spatial mismatch hypothesis as a dynamic residential sorter by minority status or skill level. Schelling has also identified self-organising processes where economic agents tip into segregated use of space (Meen and Meen, 2003). Neighbourhood quality and amenities are likely to be capitalised into house prices and rents which helps to segregate neighbourhoods by income and household preferences (Kuminoff et al. 2010). Spatial patterns of segregation may therefore reflect market imperfections, market failures, preference for social mix, neighbourhood-level path dependency and the consequences of policy.

\section{Empirical analyses on accessibility as indicators of welfare}

It is clear that the processes that sort households across space are complex and interwoven. An important question is whether the net result - measured as a snapshot at a particular point in time-leaves workless households less likely to have good access to employment (an outcome that is likely to vary between cities depending on the pattern of employment and residential segmentation). One can usefully frame this question in terms of inequality of access to employment. There are two strands to this. Firstly, how unequal is accessibility? For example, in a city where employment is highly decentralised into multiple employment nodes, access to employment may be relatively evenly distributed 
across space. In such a city, the geographic pattern of households by social class, race, or worklessness will have little consequence for spatial mismatch because all dwellings will be located near an employment centre. For cities where employment is highly concentrated (in the $\mathrm{CBD}$, for example), however, access to employment will be unequally distributed across dwellings, which opens up the possibility of employment being more accessible to particular social groups if the social geography of a city is not random (Meen and Meen 2003; Kuminoff et al. 2010).

The importance for social welfare of access to services has been considered at length. Urban systems are "pools of scarce and unevenly-spread resources (...) from which residents benefit to varying degrees according to their willingness and ability to overcome physical barriers of distance as well as financial barriers to resources in the market economy (...) the spatial structure of urban systems constitutes "hidden mechanisms" which redistributes real income through the effects of differential accessibility and proximity to the city's "goods" and "bads" respectively (...)" (Knox, 1980, p.367-68; see also Pacione, 1989).

In the UK, researchers have grown familiar with indices of multiple deprivation (e.g. Macintyre et al., 2008). Normally, the analyses would include employment, occupational status and material income as key domains of deprivation at the relevant sub-local authority geography (see Pacione, 1989, for an analysis of our study area: Glasgow, Scotland). Results have been mixed. Macintyre et al. (2008) found that some resources had higher densities in deprived neighbourhoods, and other resources were more abundant in affluent neighbourhoods. The relationship between area deprivation and access tends to vary by resource and national context (Macintyre et al., 2008).

The second strand is the apparent omission across these diverse literatures of an established methodology for how we measure the inequalities in wellbeing associated with access to employment, taking into the account the possible reductions in welfare that might be associated with close proximity to employment (this can cause house prices to rise initially as distance from an employment node increases, and then fall due to commuting costs, leading to "nonmonotonicity" in the house price gradient—see Osland and Pryce, 2012). There has been no shortage of discussion and speculation on the causal mechanisms that drive spatial mismatch and sorting processes (see our review above and also Meen and Meen, 2003, and Kuminoff et al., 2010), but how do we measure the outcome at a given point in time in a meaningful way? It is true that such a snapshot may 
capture a moment of disequilibrium in the urban economy, but this takes little away from the benefits of comparative statics because it is perfectly possible - even likely - that the urban economy is perpetually adjusting, and is understood best as a system in dynamic disequilibrium. Given the complexity of such a system, repeated snapshots will continue to have a potentially important role in helping us describe and understand that system.

The question, then, is how to take such a snapshot given the nonmonotonicities and polycentricities noted above, and how do we relate the findings to issues of spatial mismatch and inequality? As far as we can see, there is little research that relates inequality issues, land rent gradients, and access to employment. Wang (2003), for example, explores job proximity and worker welfare, but does not explore the hedonic house price issues.

In summary, we would like to find a way of measuring the distribution of welfare associated with access to employment at a given point in time. This would be useful because it would allow us to explore how the geographic pattern of this variable corresponds to patterns of deprivation, unemployment and other social indicators. This would then open avenues for further research that are potentially important for planning and social security. For example, if one were to observe that market allocations of land and property resulted in unemployed workers being relegated to areas with low levels of welfare associated with access to employment this would provide de facto case for exploring spatially targeted intervention strategies that seek to redress the imbalance. Such strategies might include providing low income workers and job seekers financial assistance to help reduce commuting costs (Thakuriah et al. 2013). Similarly, when constructing social housing estates, planners would find it helpful to know the optimal location of such dwellings in terms of the estimated welfare associated with access to employment, taking into account offsetting negative externality effects.

\section{Research Questions}

We seek to investigate the following research questions:

1. How unequal is the wellbeing derived from access to employment across the city? 
That is, we seek to estimate the distribution of "Access Welfare" across locations in Glasgow, and to use standard measures of inequality to gauge how unequal that distribution is across space.

2. What is the monetary value placed on access to employment

In contrast with traditional geographical approaches we seek to estimate the financial value that society places on being located in close proximity to employment, mindful of the fact that there may be many employment nodes of varying size and offsetting factors (noise, pollution, congestion) associated with living near a centre of employment.

3. How does the inequality of access to employment correspond to the geographical pattern of unemployment?

In other words, are those who are out of work most likely to be located in areas with low levels of welfare from measured access to employment? This is an important question because it potentially relates the location of unemployment to past and prospective planning decisions, and the extent to which house prices assist the spatial sorting of households across urban space.

\section{Methods}

\section{Methodological Issues:}

If we ask how the distribution of Access Welfare varies by income group, then an important consideration will be how employment access may itself affect earning potential. The direction of causation may run both ways. In the long run, the earning potential associated with locating in a particular area will affect the price of housing in that area, but the effect is complicated by other factors. For example, higher income households demand more space, so they may be inclined to live further away from employment centres where land plots are larger and cheaper per $\mathrm{m}^{2}$. At the same time, however, such households have a higher opportunity cost of time, significantly raising commuting costs per kilometre relative to poorer households. Nevertheless, the geographical pattern of house prices observed in a given moment should indeed reveal the wellbeing associated with employment access, if we can control for other factors that affect house prices, and if house prices are approximately in equilibrium. We should 
describe our results with caution because of the difficulties in controlling for other factors and because of the potentially dynamic and circular relationship with income.

A second concern is that planners have limited control over the location of firms. They can zone land use, offer financial incentives and direct planning permission, but cannot force firms to locate in a particular area. One factor affecting the location decision of firms is the pool of skilled labour. A second is the proximity to market: other things being equal, firms seek to minimise distribution costs. This in turn is affected by the location of high earners, so it may be that employment location follows income rather than the other way round (evidence of firm location following skilled labour residential location clusters can be found in analysis by Meen et al., 2001). Consequently, we do not present our analysis of the correspondence between Access Welfare and income as a strictly causal one, rather we simply describe the spatial pattern observed.

A third issue is how we measure labour market accessibility. This is complicated considerably by the possibility of multiple employment nodes. To work out the commuting times and costs across multiple modes of transport from every dwelling to every employment node is prohibitively complex. Even using simple Euclidean distance from every dwelling to every employment node - the approach adopted here-is computationally challenging (there are 6,269 dwellings in our data, and 6,501 potential employment nodes, yielding 40 million distances). The potential non-monotonicity in the relationship between access and welfare adds further to the complexity, which we tackle using the Osland and Pryce (2012) model (details below).

Using Euclidean distances nevertheless raises the question of whether we are introducing a major source of bias. For example, journey times for a given Euclidean distance might vary according to whether the resident lives in a high or low-density area. Duranton and Overman (2005, p.1083), in their landmark paper, argue that there is no obvious bias because opposing effects are at work: "In low-density areas, roads are fewer (so actual journey distances are much longer than Euclidean distances) whereas in highdensity areas they are more numerous (so Euclidean distances are a good approximation to actual) but also more congested". They also cite empirical evidence from Combes and Lafourcade (2005), who find that "the correlation between Euclidean distances and generalized transport costs (computed from real transport data) ... is extremely high at 0.97" (Duranton and Overman, 2005, p.1083).

A fourth concern is whether house price data can capture sufficient information about spatial inequality in employment in areas dominated by social renting. This is 
especially important as spatial concentration of social housing is associated with a variety of disadvantages (income, employment, obstacles to employment such as disability etc. see Hills, 2007). One important development that goes some way to ameliorate this concern is the advent of Right to Buy. Because social housing can now be purchased and resold into owner occupancy (and may often end up in the private rented sector), areas that were once exclusively social renting (and remain primarily so) will now be represented in a dataset of private house transactions. The price differentials in those sales will allow us to pick up variations in quality of life, holding constant the type and size of property. Inevitably, however, such sales are sparse relative to areas that are dominated by owner occupancy or private renting ${ }^{1}$ and there may be sample selection problems. Moreover, there have been attempts to 'mix' tenure in new neighbourhoods ${ }^{2}$ and existing communities which may have further dilute the spatial concentrations of social housing. However, it is anticipated that the geographical variation in access to employment and other drivers of wellbeing will be so pronounced that it will dominate the loss of precision that arises from sparse observations. Moreover, we include a number of neighbourhood variables which will further help capture the effects of social housing estates.

\section{Econometric Strategy}

As noted, our estimation method needs to address the problem of multiple employment nodes and the complication that the effects of distance may be nonmonotonic due to the externality effects of close proximity to employment centres. In short, we need to find a way of modelling the relationship between access to employment and house prices that does not impose monotonicity, and that captures the effect of proximity to many employment centres, each of varying size in terms of numbers employed.

Early studies of the effects on house prices of distance to employment simply computed the distance from each dwelling to the CBD, ignoring suburban employment locations. In this paper we use a gravity based accessibility measure and maximum likelihood (ML) methods to estimate (rather than assume) the appropriate functional form. This is important since urban theory does not give us precise guidance on how to

\footnotetext{
${ }^{1}$ Dwellings used for private renting also enter databases on house transactions because private landlords buy and sell properties.

${ }^{2}$ such as the use by local authorities of Section 106 of the UK Town and Country Planning Act 1990 to encourage the construction of affordable housing.
} 
weight distance vs. size of employment node. Osland and Thorsen (2008) illustrates how the relative effects can be estimated by including separate parameters for distance and number of employees. Osland and Pryce (2012) further develop this approach to allow for non-monotonic distance effects by including a third non-linear parameter, theta. We also need to account for unobserved spatial heterogeneity arising, for example, from uncaptured amenity values. Osland and Pryce (2012) test for and incorporate such effects using spatial econometric methods, summarised below.

Applying the Osland and Pryce (2012) estimated econometric functional form, we relate the price of homogenous housing at a given location to the gravity based access variable, $S_{j}$, where $S_{j}=\sum_{j} L_{j}^{\gamma} v_{i j}{ }^{\theta} \exp \left[\sigma_{i j}\right]$. We interpret the $S_{j}$ variable as an indicator of the wellbeing or welfare that arises from access to employment: $S_{j}$ is defined as our Access Welfare variable. Note that by estimating the values of parameters $\gamma, \theta$ and $\sigma$, we are able to take into account the effect of varying size of employment nodes $(L)$, and the potentially non-linear and non-monotonic effects of distance $(v)$ on welfare. That is, $S_{j}$ can rise with proximity to employment nodes but then decline as one approaches close proximity.

We follow the convention of using the log of house prices as the dependent variable (see Malpezzi 2003 p.80 for a summary of the main reasons why this has become the preferred approach). This leaves us with the following model:

$$
\begin{aligned}
& \ln (P)=a_{0}+\mathbf{b} \cdot \mathbf{A}+a_{1} \sum_{j} L_{j}^{\gamma} v_{i j}{ }^{\theta} \exp \left[\sigma v_{i j}\right] \\
& +a_{2} C B D+a_{3} \text { Seas_d } d+a_{4} D+i \text { Subm_d } d+a_{5} \text { SPerf }+\varepsilon
\end{aligned}
$$

where $P=$ observed selling price at location $i, \mathbf{A}$ is a vector of attributes of dwelling at location $i$, and CBD is the distance to the central business district. The variables contained in $\mathbf{A}$ are: dwelling type (house or flat, conversion, detached, semi-detached, detached bungalow, detached villa), internal characteristics (traditional construction, bay window, number of bedrooms, number of public rooms, ensuite bathrooms, gas central heating, whether the property needs upgrading, whether the property is described as luxurious), external characteristics (whether plot is measured in acres, whether there is a garden, garage, parking and notable views), CBD is included to test whether there are any effects of proximity to $\mathrm{CBD}$ other than the access to employment effect (Brueckner et al., 1999; Osland and Thorsen, 2008). The model is adjusted for time of sale, and hence, 
seasonal dummies Seas_d are included. D denotes deprivation score. We use the Scottish Index of Multiple Deprivation (SIMD) that combines 38 indicators across the domains of income, employment, health, education, skills, training, housing, geographic access to a range of services and crime measured at Datazone level, where each Datazone is made up of around 800 individuals (including children) on average ${ }^{3}$. The variable SPerf denotes school performance, and has been shown to be of importance in the housing submarket literature (see for instance Goodman and Thibodeau 1998). Subm_d denotes the inclusion of submarket dummies. Our data area is divided into four submarkets: the West End, East End, South Side and North Side. A dummy variable for each of these submarkets in included in the model, except for the West End, which we treat as the reference category.

Note that the boundaries of these submarkets are based on estate agent jurisdictions. While this is an established procedure in the literature (see discussion and review in Pryce and Gibb, 2006, pages 383 and 394), it is important to understand the limitations of this a priori approach. Pryce (2013) for example, demonstrates how "true" submarket boundaries-defined in terms of dwelling substitutability-may be considerably more fragmented, nuanced and complex than those imposed using predetermined jurisdictions. Note also that the submarkets used here represent relatively large areas, and so it is possible that there will exist uncaptured amenity values and unobserved spatial variation in dwelling attributes within these submarkets (Osland, 2010).

As such, it is important to subject any cross-sectional hedonic regression model of this kind to thorough testing, particularly with respect to spatial autocorrelation and spatial heterogeneity (Anselin, 1988), as it is to be expected that a mixture of these effects will be present. The Moran's I test for our model, for example, showed that the null hypothesis of no spatial effects should be rejected. The subsequent, Lagrange multiplier tests indicated that spatial heterogeneity was the main problem. The p-values for all the mentioned tests of spatial effects were 0.000 .

What is the implication of spatial heterogeneity? The most common consequence is heteroscedastic errors (Can 1990). In order to study to what extent possible spatial misspecifications could be a problem in the estimated hedonic model, a Spatial Durbin

\footnotetext{
3 There are 6,505 datazones in Scotland, which has a total population of around 5,255,000. So, on average, there are around 800 individuals (including children) per datazone. This is a much smaller level of geography for the analysis of social data than is provided in most countries: US Census Tracts, for example, usually have between 2,500 and 8,000 persons (http://www.census.gov/geo/www/cen_tract.html). This is likely to reduce considerably the levels of aggregation bias associated with area-based measures. For further information on Datazones, measures of deprivation and other Scottish social variables, see:www.sns.gov.uk
} 
model was estimated. This model has been shown to be robust to a range of spatially related misspecifications (LeSage and Pace, 2009). We compared the estimated impacts from the Spatial Durbin model to the OLS results, along with an extensive set of other comparisons and tests. Given the robustness of the Spatial Durbin model, this analysis enabled us to conclude that the OLS estimators relating to the labour market accessibility variable were statistically significant and probably represented the upper bound to the average total impact of labour market accessibility on housing prices. Spatial heterogeneity is, therefore, most likely not causing any serious bias to the estimated parameters related to this variable. See Section 5 below for further comments on this issue and Osland and Pryce (2012) for full details of the extensive diagnostic process. Note also that even when we omitted the submarket, deprivation and/or distance to CBD variables entirely (see R3 and R4 in Table 2 of Osland and Pryce , 2012), the access to employment variable remained highly statistically significant, and the coefficient remained relatively stable. Moreover, $\gamma$, the non-monotonicity parameter, remained significantly greater than zero throughout all these model permutations, confirming the non-monotonic distance to employment effect on house prices (and hence on household welfare).

\section{Measuring Inequality:}

We employ Kernel density estimation and Gini coefficients to measure inequality. Kernel density estimation is a non-parametric approach to estimating the probability density function of a variable. The probability density function is a mathematical representation of the distribution of a variable. It is similar to a histogram except that the vertical axis is standardised to ensure that the area under the distribution equals one. Also, the density curve is more precise than a histogram in the sense that it shows the shape of the distribution as a continuous line rather than as a series of discrete columns. We estimate the shape of the distribution using Kernel density methods which are nonparametric and so do not assume a particular shape to the distribution (i.e. it means that we do not have to assume that employment access is normally distributed, for example). In terms of our current requirements, Kernel density estimation allows us to simulate the shape of the distribution and hence helps us visualise how unequal access to employment actually is. If there is complete equality in access, then the density function will appear as 
a single spike - every observation will have the same value. The greater the inequality in access, the more spread out the distribution will be.

The Gini coefficient takes on a value between zero and one, and can be represented as a percentage (Johnson, 1973; Lambert 1993). If access to employment is perfectly equally distributed, the Gini coefficient will equal zero. In a perfectly unequal distribution, the coefficient will equal one. We apply the Gini measure of inequality to the Access Welfare variable. ${ }^{4}$

\section{Data}

The variables of our model are summarised below in Table 1. The house price data are based on transaction prices supplied by Glasgow Solicitors Property Centre, a consortium of over 200 real estate agents across the Strathclyde city region, and are comprised of 6,269 dwelling transactions in Glasgow, Scotland, in 2007. The dataset has a relatively dense spatial distribution: most observations lie within about $10 \mathrm{~km}$ of the centre of Glasgow; the maximum distance for any observation from the centre is about 30 $\mathrm{km}$. In order to identify the relationship between house prices and labour market accessibility, we need to allow for the fact that some may commute to surrounding towns and cities to work. This calls for the use of a relatively large geographical area as the basis of our possible employment locations.

\section{Table 1 Descriptive statistics}

Glasgow is the largest city in Scotland (a population of 589,000 in 2009 according to the Glasgow Economic Commission ${ }^{5}$ and is the core city of the Clydeside conurbation (population 1.73 million $^{6}$ ). Originally characterised by shipbuilding, engineering, chemical and extractive industries, the City went into long term economic decline. Over the last 30 years it has been restructured into an economy based more on producer services, public sector employment, finance, food and drink (Glasgow City Council, 2010). Despite strong job growth in the period up to the recent recession, the City still

\footnotetext{
${ }^{4}$ Atkinson coefficients were also computed and are available from http://dl.dropbox.com/u/988239/AdditionalMaterial.doc or on request.

${ }^{5} \mathrm{http}: / /$ www.glasgoweconomicfacts.com/Dept.aspx?dept_id=191

${ }^{6}$ According to the Glasgow and Clyde Valley Joint Structure Plan website, accessed February 18 2011, see http://www.gcvcore.gov.uk/facts_figures/facts.htm
} 
nonetheless bears the legacy of economic restructuring in terms of relatively high levels of unemployment, economic inactivity and benefit dependence (Scottish Government Local Authority Economic Profiles, sourced 18 February $2011^{7}$ ). Spatially, there is considerable inequality as measured by health, education and broader measures of multiple deprivation (Scottish Government National Statistics, 2009). A detailed description of the prices, house types, landscape, neighbourhood characteristics and access to various amenities across Glasgow is found in Pryce and Gibb (2006).

\section{Results}

\section{Regression Results}

The specification of the Access Welfare variable set out in (1) is non-linear in parameters. For this reason ML estimations have been performed to obtain optimal values of the parameters. In this way, all the parameters have been estimated simultaneously. Thereafter we have performed least squares estimation of (1) based on imputed values of the estimated parameters found in the Access Welfare variable.

For further information on the analysis of the error term and the relationships between variables, we refer the reader to a very detailed account of these issues in the sister-paper: Osland and Pryce (2012) which is devoted to the development of the spatial econometric model utilised in the current paper. Note, however, that while the Osland and Pryce (2012) paper develops the robust econometric exploited here, it does not compute the welfare access variable. Nor does it consider the distribution of that variable across space, or how it relates to the spatial mismatch hypothesis.

In summary, the results in Osland and Pryce (2012) clearly showed that the Access Welfare variable contributes significantly to explain variation in housing prices in the Glasgow area. The variable is most significant when monotonicity is not imposed. To further substantiate this result, Osland and Pryce (2012) estimated a variety of more complex model alternatives for various spatially related misspecifications. Regardless of spatial model, ${ }^{8}$ estimation method or weights matrix computation, the labour market accessibility variable with a non-monotonic distance effect was important for explaining variation in housing prices. The overall conclusion from Osland and Pryce (2012) is that

\footnotetext{
${ }^{7}$ http://www.scotland.gov.uk/Topics/Statistics/Browse/Labour-Market/ProfileGlasgowCity

${ }^{8}$ i.e. spatial error model, spatial lag model or a more comprehensive spatial Durbin model
} 
the spatial error model can be used as an approximation of the average total impact of changes in accessibility on house prices, whereas the results from the OLS model (used here) can represent an approximate upper bound to this effect.

Results from the final chosen model based on OLS-estimations are available on request. ${ }^{9}$ We assessed the importance of each variable by computing standardized coefficients and found that the parameter related to the accessibility variable is the second most important variable. Given the distributional issue studied in this paper, it could be argued that we should consider whether the estimated monetary impact of access is the same for the whole distribution of the dependent variable. For this reason we also estimated quantile regressions and found that the estimated effect of accessibility is remarkably stable for the total distribution of house prices. In all these cases, the estimates are within the $95 \%$ confidence region of the OLS-estimate.

\section{How unequal is access to employment across the city?}

We have created an Access Welfare Variable, $S_{j}$, that captures the benefits of access to employment while taking into account the undesirable effects of being located too close to an employment node. We have estimated its Kernel density function in Figure 1 below for Glasgow (dropping out repeat postcodes). While no household has zero welfare, over 7 per cent of people have access welfare values less than 1, and a further 11 per cent have values less than 10 , either because they are located very near employment centres (and therefore suffer from noise, pollution and congestion) or very far from employment nodes. Access to employment is highly unequal with the average variation in Access Welfare coming in at around $90 \%$ of the mean (as shown by the coefficient of variation). The Gini coefficient of .48 (relative to a value of zero in a world of equal access and a value of 1 in a world of perfect unequal access) paints a similar picture. ${ }^{10}$

\footnotetext{
${ }^{9}$ Or downloadable from http://dl.dropbox.com/u/988239/AdditionalMaterial.doc

${ }^{10}$ As do the Atkinson coefficients-see Table 3 and footnote 3 above.
} 
Figure 1: Density Function Estimate for Access Welfare $\left(S_{j}\right)$ and the Monetary

Value of Access to Employment (MVAW)

\section{Table 2: Summary Statistics for the Access Welfare Variable (S) and the Monetary Value of Access Welfare (MVAW)}

2. What is the monetary value placed on access to employment?

One limitation of the $S_{j}$ variable is that it does not have an obvious scale. This makes it difficult to interpret. We know, in principle, that $S_{j}$ has a one-to-one mapping with the wellbeing associated with access to employment (the higher the value of $S_{j}$ the greater the wellbeing) but the numbers themselves do not relate to recognisable units of measurement. To make the numbers more meaningful we attempt to estimate the financial value that society places on being located in close proximity to employment, incorporating offsetting factors of negative externalities. To convert the $S_{j}$ variable to a monetary scale, we use our regression model to compare the predicted value of each house in our sample with that of a dwelling with zero access.

The results are presented in Figure 1 in terms of a Kernel density estimate of the distribution of MVAW (the Monetary Value of Access Welfare) across space. Summary statistics describing the mean and dispersion of the distribution are listed in Table 2. Again, all results indicate considerable inequality in MVAW, with a coefficient of variation of $110 \%$ and a Gini coefficient of $52 \%$. This suggests that MVAW in Glasgow is considerably more unequal than both house prices and income, which have Gini coefficients of 0.30 and 0.31 respectively (Table 3). MVAW is even more unequal than homeowner income in the UK as a whole (Gini coefficient $=0.36$ ). The disparity between Atkinson coefficients is even greater (Table 3).

\section{Table 3: Inequality Measures for the Monetary Value of Access Welfare Variable (MVAW)}

Our results show that the value of access to employment in houses in Glasgow is, on average, $£ 18,551.69$. That is, averaging across locations and house types, access to polycentric employment, when capitalised into home value, is typically worth $13 \%$ of the 
value of an average house. This confirms that access to employment is important to homeowners and therefore valuable. And if valuable, it is likely to be unequally allocated in a market system because income, wealth and human capital are unequally distributed.

\section{How does the inequality of access to employment correspond to the geographical pattern of variation in unemployment?}

Who receives the most welfare gains from access to employment, those in employment or those seeking employment? This is an important question because it potentially relates the consequences of land use and strategic planning decisions to social and economic inequality. It also connects our results to the predictions of urban economic theory which traditionally places higher income households further from employment nodes.

Visual comparison of 3D surface plots of MVAW and of unemployment across space $^{11}$ revealed no obvious negative correlation (as predicted by the spatial mismatch hypothesis). If anything, there is a possible positive correlation: high rates of unemployment occur in areas with good access to employment. Table 4 reports four regressions, each with the unemployment rate as the dependent variable. All variables are in logs so coefficients are interpreted as elasticities and are measured at datazone level. Column R1 reports the results of a regression of unemployment on the number of employees. We would expect a negative sign if there was evidence of spatial mismatch. The elasticity of unemployment with respect to employment is, however, very slightly positive, which suggests that areas with high levels of employment also tend to have above average unemployment. The disadvantage with using the datazone employment levels to assess spatial mismatch is that a household could be located in a datazone with low levels of employment, but be surrounded by datazones with high levels of employment. Also, being located in very close proximity to an employment centre might bring with it negative externalities as noted above. In regression R2, therefore, MVAW is used as the regressor. If there was a high degree of spatial mismatch, we would expect the elasticity to be highly negative: i.e. the greater the MVAW, the lower the unemployment

\footnotetext{
11 Estimated using nearest neighbour methods. The results of which are available on request or from: http://dl.dropbox.com/u/988239/AdditionalMaterial.doc
} 
rate. In fact, the coefficient is not significantly different to zero, suggesting no relationship. Regression R3 includes both MVAW and employment as explanatory variables, and confirms the results of R1 and R2: employment has a modest but significant, positive relationship; MVAW has no significant relationship with unemployment.

Regression R4 includes house prices along with these two explanatory variables in order to explore whether there is evidence of sorting: i.e. unemployment is lower in areas with higher average house price. This does, indeed, appear to be the case: the elasticity of unemployment with respect to house price is -0.75 , which suggests that areas with $10 \%$ higher house prices will have unemployment rates that are $7.5 \%$ lower. In this final regression, the MVAW elasticity, along with the employees elasticity, is statistically significant and positive, but modestly so-i.e. unemployment rates are highly inelastic with respect to both MVAW and employment.

One should be cautious when interpreting the unemployment regressions - they are reported for descriptive purposes only (as discussed earlier, the direction of causation is ambiguous). However, what we can say is that these results do not provide de facto confirmatory evidence of a spatial mismatch in Glasgow, at least not with respect to total unemployment rates (e.g. it remains possible that there may exist spatial mismatches for particular categories of unemployed worker, such as those with particular skill sets).

\section{Table 4: Unemployment Regressions (for descriptive purposes)}

\section{Conclusion}

This paper has sought to address three research questions: (1) How unequal is the wellbeing derived from access to employment? (2) What is the monetary value placed on access to employment? (3) How does the inequality of access to employment correspond to the geographical pattern of variation in unemployment? We have proceeded to answer these questions on the basis that house prices, once adjusted for property type and size, will reflect variation in the quality of life across space. We derive econometric estimates on this basis of the impact of employment access on house prices.

Our approach has been novel in that we have addressed both the highly non-linear relationship between wellbeing and distance to employment, and the existence of multiple centres of employment nodes, each of a different size. We are aware that this 
study is nevertheless a static one and cannot tackle the difficult problems of causality and simultaneous determination. We are also aware of multiple sources of imprecision and bias in our model (not least the relatively sparse observations on house prices in the most deprived areas). Nevertheless, we believe that our key results (the inequality of access and the inelasticity of unemployment with respect to the monetary value of access) are so pronounced that they are unlikely to be overturned by using more precise refined data.

It is beyond the scope of this paper to estimate the extent to which the weak relationship between the location of those who need work and the location of employment is due to the sorting process of the market, and the extent to which it is due to the cumulative history of planning decisions (for instance, slum clearance and the location of peripheral social housing estates in the post war period and the economic location of business investment to Clydeside new towns). The two are inevitably interlaced. Nevertheless, our results suggest that the net result of these processes has not led to a spatial mismatch in Glasgow, at least not for the unemployed as a whole.

It is possible, however, that spatial mismatches may exist for particular categories of worker, such as those with low skill levels, or those unable to commute long distances to work. In which case, the fundamental processes underlying spatial mismatch and corrective policies suggested by Gobillon et al. (2007) may still be relevant. These include helping disadvantaged groups to locate closer to job opportunities, attracting adequate jobs to city centres (or close to where the disadvantaged currently reside), or improving informational/physical connections between jobs and workers (p.2417)). The appropriate route depends on the prevailing mechanism of mismatch which may not imply a one-size-fits-all solution.

Our findings also raise the question of whether a model of this kind might provide a practical input into strategic planning generally. The model is useful because is makes explicit the juxtaposition of residential and employment location and estimates the implications for equality of access. Our findings highlight important questions about the priorities of planning policy and whether equality of access (based on models of the type proposed here) should be an active ingredient of strategic planning decisions. Our model could also be used to simulate the impact on employment access inequality and spatial mismatch of new developments, such as the construction of a new factory. It would be relatively straightforward to use our model to simulate the effect on Access Welfare (and the corresponding Gini coefficients) of hypothetical increases in employment in 
particular datazones, for example. The model could also contribute to the benefit-cost analysis of major potential transport investments.

We should note, in closing, that there are a number of significant limitations to our analysis, each of which imply important avenues for future work. Firstly, we have used Euclidean distance as a proxy for employment access. While we cited reasons to believe this is a good approximation, ideally a variety of different measures should be compared. Moreover, it would be useful to explore whether the effectiveness of public transport (e.g. a relatively cheap bus service to employment nodes, or subsidised transport services for low-wage, carless workers-see Thakuriah et al. 2013) can compensate for inequalities in employment access. Secondly, we have focused on the spatial mismatch hypothesis by comparing access to employment with the distribution of unemployed workers. However, we have not considered the pattern of skills, either of unemployed workers or of those utilised in employment nodes. Thirdly, we have not explored, in any great depth, the particular role played by social housing.

Fourthly, we have not sought in this paper to address the profound endogeneity of household location, house value, employment location, socio-economic composition of neighourhoods, access to social, cultural and educational amenities. Our models have not intended to be causal. Instead, for the reasons outlined in section 1, our focus has been on the description of relationships between house values and employment access at particular snapshots in time. Nevertheless, our results inevitably raise questions about the causal processes that have led to the observed pattern of inequality in access welfare. Until relatively recently, methodological and data limitations would have precluded meaningful analysis of this question. However, the advent of empirical sorting models (Kuminoff et al. 2010) and continued rapid development of new methods and data relevant to this field, offer the tantalising prospect of being able to develop meaningful models of the underlying causal processes that drive spatial patterns of unemployment, income, ethnicity and proximity to employment. So, an important priority for future research will be to exploit sorting model technologies to tackle directly questions of how spatial mismatch and inequality in access welfare are determined. Such models may also allow us to disentangle the implications of heterogeneous preferences-different households and different socio-economic groups may have different preferences for access to employment, commuting, and the work-leisure trade-off. 


\section{References}

Anas A., A. Richard, and K. Small (1998) “Urban Spatial Structure,” Journal of Economic Literature, 36(3), 1426-1464.

Blumenberg, E. and Manville, M. (2004) Beyond the Spatial Mismatch, Journal of Planning Literature, 19(2), 182-205.

Brueckner, J. K., Thisse, J.-F. and Zenou, Y. (1999) Why Is Central Paris Rich and Downtown Detroit Poor? European Economic Review, 43(1), 91-107.

Can, A. (1990) The Measurement of Neighborhood Dynamics in Urban House Prices. Economic Geography, 66(3), 254-72.

Evans A.W. (1985) Urban Economics, Basil Blackwell, Oxford.

Glasgow City Council (2010) Glasgow Economic Review November 2010. Glasgow City Council: Glasgow.

Gobillon, L., H. Selod,and Y. Zenou (2007) The Mechanisms of Spatial Mismatch, Urban Studies, 44(12), 2401-2427.

Goodman, A.C. and Thibodeau, T.G. (1998) Housing Market Segmentation. Journal of Housing Economics, 7, 121-143.

Hills, J. (2007) Ends \& Means: The Future Roles of Social Housing in England, Report 34, Research Centre for the Analysis of Social Exclusion: London.

Houston, D. (2005) Employability, Skills Mismatch and Spatial Mismatch in Metropolitan Labour Markets, Urban Studies, 42(2), 221-243.

Ihlanfeldt, K.R. and Sjoquist, D.L. (1998) The Spatial Mismatch Hypothesis: A Review Of Recent Studies and their Implications for Welfare Reform, Housing Policy Debate, 9(4), 849-892.

Kain, J.F. (1968) Housing Segregation, Negro Employment, and Metropolitan Decentralization. Quarterly Journal of Economics 82(2), 175-97.

Kain, J. (2004) A Pioneer's Perspective on the Spatial Mismatch Literature, Urban Studies, 41, 7-32.

Knox, P.L. (1980) Measures of Accessibility as Social Indicators: A Note, Social Indicator Research, 7, 367-377.

Kuminoff, N.V., V.K. Smith, and C. Timmins (2010): "The New Economics of Equilibrium Sorting and Its Transformational Role for Policy Evaluations”, NBER Working Paper No. 16349. 
Macintyre, S., Macdonald, L., and Ellaway, A. (2008) Do poorer People Have Poorer Access to Local Resources and Facilities? Social Science \& Medicine, 67, 900914.

Maclennan, D. (1982) Housing Economics. Longmans: Harlow, Essex.

McDonald J.F. and D.P. McMillen, 2007, Urban Economics and Real Estate: Theory and Policy, Blackwell, Malden.

Meen, G, Gibb, K, Mackay, D and White, M (2001) The Economic Role of New Housing: Report to the Housing Research Foundation. London: Housing Research Foundation.

Meen, D. and Meen, G. (2003) Social Behaviour as a Basis for Modelling the Urban Housing Market: A Review, Urban Studies 40, 917-935.

Mieszkowski, P and Mills, E.S. (1993) The Causes of Metropolitan Suburbanization, Journal of Economic Perspectives, 7(3), 135-147.

Mills, E.S. (1972) Studies in the structure of the urban economy. Johns Hopkins University Press, Baltimore.

Morrison, P.S. (2005) Unemployment and Urban Labour Markets, Urban Studies, 42(12), 2261-2288.

Muth, R, 1969, Cities and Housing, Chicago, University of Chicago Press.

Osland, L. \& Pryce, G. (2012) Polycentric Access to Employment with Non-Monotonic Distance Effects, Housing Studies, 27(8) 1182-1208

Osland, L. (2010): "An Application of Spatial Econometrics in Relation to Hedonic House Price Modelling"'. Journal of Real Estate Research, 32(3), pp. 289-320.

Osland, L. and Thorsen, I. (2008) Effects on Housing Prices of Urban Attraction and Labor Market Accessibility, Environment and Planning A, 40(10), 2490-2509.

Pacione, M. (1989) Access to Urban Services, Scottish Geographical Magazine, 105(1), 12-18.

Preston, V. and Mclafferty, S. (1999) Spatial Mismatch Research in the 1990's, Papers in Regional Science, 78, 387-402.

Pryce, G. (2013) Housing Sub-markets and the Lattice of Substitution, Urban Studies, DOI: $10.1177 / 0042098013482502$

Pryce, G. and Gibb, K. (2006) Submarket Dynamics of Time to Sale, Real Estate Economics, 34(3), 377-415.

Scottish Government National Statistics (2009) Scottish Index of Multiple Deprivation 2009 General Report. Scottish Government National Statistics: Edinburgh. 
Thakuriah, P., Persky, J., Soot, S., and Sriraj, P.S. (2013) Costs and benefits of employment transportation for low-wage workers: An assessment of job access public transportation services, Evaluation and Program Planning, 37, 31-42

Tiebout, C.M. (1956) A Pure Theory of Local Expenditure, Journal of Political Economy, 64(5), 416-424.

Turok, I. and Webster, D. (1998) The New Deal: Jeopardized by the Geography of Unemployment? Local Economy, 12(4) 309-328.

Wang, F., (2003) Job Proximity and Accessibility for Workers of Various Wage Groups, Urban Geography, 24(3), 253-271. 
Table 1 Descriptive Statistics

\begin{tabular}{|c|c|c|c|}
\hline & Variable Name & Mean & Standard Deviation \\
\hline & Selling price (GBP) & $139,850.00$ & $75,714.17$ \\
\hline \multirow[t]{5}{*}{ Type of Dwelling } & House & 0.2792 & 0.4486 \\
\hline & Conversion & 0.0182 & 0.1336 \\
\hline & Detached Bungalow & 0.0227 & 0.1488 \\
\hline & Semi detached bungalow & 0.0188 & 0.1359 \\
\hline & Detached Villa & 0.0638 & 0.2444 \\
\hline \multirow{8}{*}{$\begin{array}{l}\text { Internal } \\
\text { Characteristics \& } \\
\text { Size }\end{array}$} & Traditional & 0.1050 & 0.3065 \\
\hline & Bay & 0.1916 & 0.3936 \\
\hline & Bedrooms & 2.2450 & 0.8900 \\
\hline & Public rooms & 1.2770 & 0.5735 \\
\hline & Ensuite & 0.0518 & 0.2217 \\
\hline & Gas Central Heating & 0.6168 & 0.4862 \\
\hline & Needs upgrading & 0.0193 & 0.1376 \\
\hline & Luxury & 0.0284 & 0.1661 \\
\hline \multirow{5}{*}{$\begin{array}{l}\text { External } \\
\text { Characteristics \& } \\
\text { Size }\end{array}$} & Plot measured in Acres & 0.0016 & 0.0399 \\
\hline & Garden & 0.7212 & 0.4485 \\
\hline & Garage & 0.2346 & 0.4238 \\
\hline & Parking & 0.1099 & 0.3128 \\
\hline & Views & 0.0526 & 0.2233 \\
\hline \multirow[t]{3}{*}{ Season } & Spring & 0.2823 & 0.4502 \\
\hline & Summer & 0.2747 & 0.4460 \\
\hline & Autumn & 0.2337 & 0.4232 \\
\hline \multirow{5}{*}{$\begin{array}{l}\text { Neighbourhood/ } \\
\text { Submarket } \\
\text { Variables }\end{array}$} & Deprivation & 5.6220 & 2.3930 \\
\hline & School Performance & 35.7866 & 22.8057 \\
\hline & eend_d & 0.0861 & 0.2806 \\
\hline & sside_d & 0.1905 & 0.3927 \\
\hline & ngla_d & 0.0322 & 0.1766 \\
\hline Distance to CBD & Distance to CBD $(\mathrm{km})$ & 8.4988 & 6.3382 \\
\hline
\end{tabular}


Figure 1: Kernel Density Function Estimate for the Access Welfare Variable (S), and the Monetary Value of Access Welfare variable (MVAW)

(a)

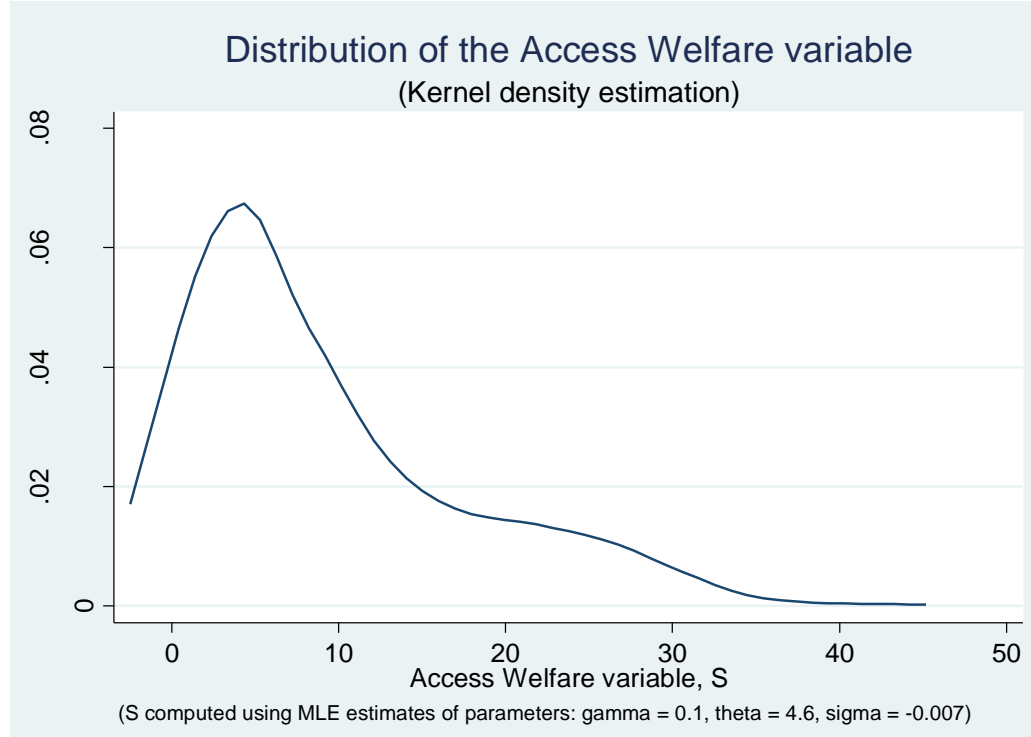

(b)

Distribution of the Money Value of Access Welfare (Kernel density estimation)

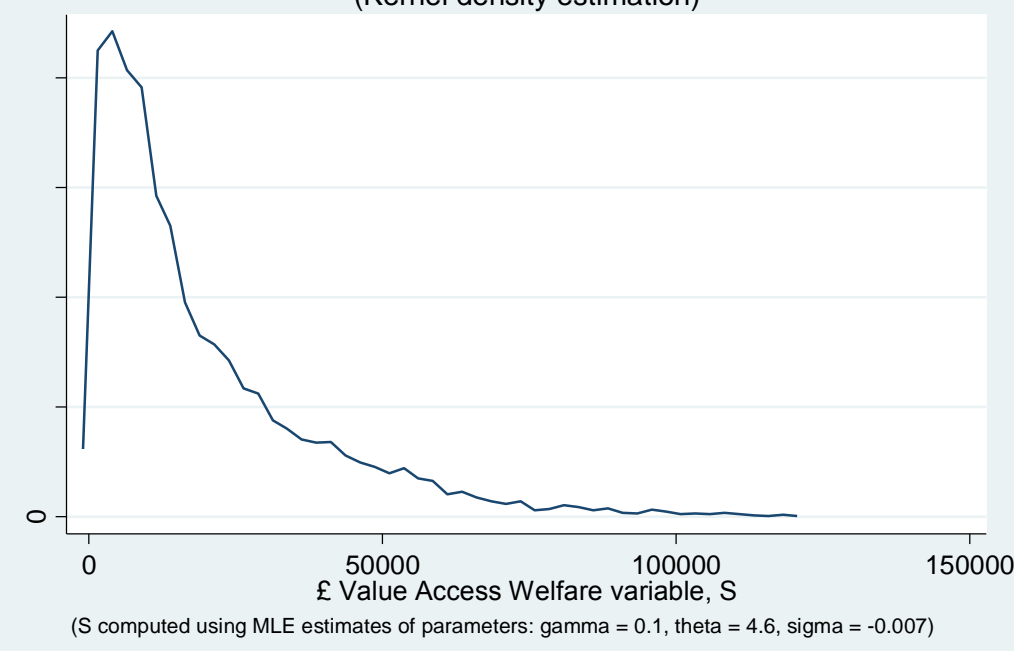


Table 2: Summary Statistics for the Access Welfare variable (S) and the Monetary Value of Access Welfare variable (MVAW)

\begin{tabular}{lcc} 
& S & MVAW \\
\hline Number of postcodes & 4,671 & 4,671 \\
Mean & 9.14 & $£ 18,551.69$ \\
Std. Dev. & 8.25 & $£ 20,260.73$ \\
Min & .004 & $£ 12.36$ \\
Max & 42.70 & $£ 231,229.70$ \\
Coefficient of variation & 0.90 & 1.09 \\
Gini coefficient & 0.48 & 0.52 \\
Atkinson epsilon $=.5$ & 0.20 & 0.23 \\
Atkinson epsilon $=1.0$ & 0.40 & 0.40 \\
Atkinson epsilon $=1.5$ & 0.61 & 0.61 \\
Atkinson epsilon = 2 & 0.81 & 0.81 \\
Note: The statistics on MVAW (Monetary Value of Access Welfare variable S) refer to the average \\
MVAW for each post code, of which there are 4,671 in our data. MVAW is the contribution to the \\
value of the house made by wellbeing generated from access to employment. Calculated by \\
comparing the predicted value of houses in each postcode assuming observed Access Welfare values \\
with the predicted value assuming zero Access Welfare.
\end{tabular}


Table 3: Inequality Measures for the Monetary Value of Access Welfare (MVAW)

\begin{tabular}{l|cccc}
\hline & $\mathrm{A}$ & $\mathrm{A}$ & $\mathrm{A}$ & Gini \\
& $\mathrm{e}=0.5$ & $\mathrm{e}=1.0$ & $\mathrm{e}=1.5$ & \\
\hline Glasgow Monetary Value of Access & $\mathbf{0 . 2 3}$ & $\mathbf{0 . 4 0}$ & $\mathbf{0 . 6 1}$ & $\mathbf{0 . 5 2}$ \\
Glasgow House Prices (CML) & 0.08 & 0.14 & 0.20 & 0.30 \\
Scottish House Prices (CML) & 0.08 & 0.15 & 0.22 & 0.31 \\
UK House Prices (CML) & 0.09 & 0.17 & 0.23 & 0.33 \\
Glasgow OO Income (CML) & 0.08 & 0.15 & 0.35 & 0.31 \\
Scottish OO Income (CML) & 0.08 & 0.15 & 0.33 & 0.31 \\
UK OO Income (CML) & 0.12 & 0.20 & 0.32 & 0.36 \\
\hline
\end{tabular}

Note: Except for the Glasgow Monetary Value of Access, the measures are provided for by the Council of Mortgage Lenders (CML). OO denotes owner occupiers. A is the Atkinson coefficient and $e$ is it's sensitivity value. 
Table 4: Unemployment Regressions (for descriptive purposes)

\begin{tabular}{l|c|ccc}
\hline Variable & $\mathrm{R} 1$ & $\mathrm{R} 2$ & $\mathrm{R} 3$ & $\mathrm{R} 4$ \\
\hline & & & & \\
$\ln (\mathrm{MVAW})$ & & 0.016 & -0.002 & 0.063 \\
& & $(0.980)$ & $(-0.109)$ & $(4.148)$ \\
$\ln ($ employees) & 0.043 & & 0.043 & 0.051 \\
& $(3.892)$ & & $(3.748)$ & $(5.188)$ \\
$\ln$ (house price) & & & & -0.754 \\
& & & & $(-18.775)$ \\
Constant & -3.740 & -3.704 & -3.740 & 4.438 \\
& $(-25.390)$ & $(-24.957)$ & $(-25.390)$ & $(10.016)$ \\
& & & & 843 \\
\hline N & 843 & 843 & 843 & 0.3076 \\
Adjusted $\mathrm{R}^{2}$ & 0.0153 & -0.0002 & 0.0142 & 0.072 \\
\hline
\end{tabular}

All variables are measured at Datazone level. Dependent variable is the natural $\log$ of unemployment rate. Figures in brackets are t-values based on White's standard errors 